\title{
Postnatal Development of Monocyte Cytokine Responses to Bacterial Lipopolysaccharide
}

\author{
STEPHANIE T. YERKOVICH, MATTHEW E. WIKSTRÖM, DEVINDA SURIYAARACHCHI, SUSAN L. PRESCOTT, \\ JOHN W. UPHAM, AND PATRICK G. HOLT
}

\author{
Faculty of Medicine and Dentistry [S.T.Y., M.E.W., D.S., J.W.U., P.G.H.], Telethon Institute for Child Health Research, and Centre for \\ Child Health Research, Department of Pediatrics [S.L.P.], The University of Western Australia, Perth WA 6872, Western Australia
}

\begin{abstract}
Early childhood is a period of heightened susceptibility to infection due to immaturity of the immune system, and the nature of these developmental deficiencies is only partially understood. In this study, we focused on the ontogeny of the innate immune system by investigating the capacity of mononuclear cells to secrete a wide spectrum of inflammatory cytokines in response to interferon (IFN)- $\gamma$ priming and lipopolysaccharide (LPS) stimulation, namely IL-6, IL-10, IL-12, IL-18, IL-23, tumor necrosis factor (TNF)- $\alpha$, and myxovirus resistance protein A, induced by type-I IFN, at several time points between birth (cord blood) and adulthood. Competence to produce all these cytokines followed a similar developmental pattern, with slow postnatal up-regulation from the response observed in cord blood. Unexpectedly, IL-6, IL-10, TNF- $\alpha$, and IFN- $\gamma$ showed slow postnatal up-regulation but also elevated cord blood responses equal to or greater than the adult level. This was transient and not observed at 2 mo of age, and was not related to predelivery stress of the newborns. Variations in Toll-like receptor (TLR)4 function may account for these age related differences in cytokine responses, as TLR4 expression on neonatal monocytes post LPS stimulation was elevated and sustained relative to infants and adults. (Pediatr Res 62: 547-552, 2007)
\end{abstract}

$\mathrm{S}$ usceptibility to infection is maximal during early childhood due to the immaturity of innate and adaptive immune mechanisms. Functional immune competence develops slowly during the preschool years [reviewed in (1)], and one of the key rate-limiting steps may be maturation of the capacity to transduce microbial signals from the outside environment. Recently, there has been rapid progress in defining how the innate immune system recognizes and responds to microbial stimuli via activation of TLR (2), triggering intracellular signaling cascades that result in the transcription of multiple genes that are involved in regulatory and effector functions. However, the precise kinetics of this maturation process at the population level remains poorly defined, and conflicting reports exist relating to age-related changes in production capacity of individual cytokines, in particular those associated with Th1 immunity. A classic example is the Th1 "gatekeeper" cytokine IL-12, which has been reported as produced at both high (3) and low levels (4) in cord blood relative to

Received March 21, 2007; accepted June 15, 2007.

Correspondence: Patrick G. Holt, D.Sc., Division of Cell Biology, Telethon Institute for Child Health Research, PO Box 855, West Perth, WA 6872, Australia; e-mail: patrick@ichr.uwa.edu.au

This work was funded by the National Health \& Medical Research Council of Australia. adults employing different detection systems. There have been similarly contrasting results presented in terms of IL-6, IL-10, and tumor necrosis factor (TNF)- $\alpha$, with some studies suggesting lower responses by cord blood cells (5-8), and others drawing opposite conclusions $(5,9-11)$. However, what is clear is that the ratio of IL- 6 to TNF- $\alpha$ is higher in newborn cord blood monocytes compared with adult monocytes $(7,12)$. Similarly, there is general agreement that production of interferon (IFN)- $\gamma$ and IL-18 in cord blood is reduced compared with adults $(13,14)$, however, this may not necessarily apply to all cell types (15).

In the present study, we have readdressed these questions focusing on a wide spectrum of proinflammatory cytokines, notably IL-6, IL-10, IL-12, IL-18, IL-23, TNF- $\alpha$, and type-I IFN, within a single, standardized study matrix based on optimal stimulation of the innate immune system. IFN- $\gamma$ priming was utilized to permit production of IL-12 as part of the response to lipopolysaccharide (LPS) (16). Additionally, based on findings from an earlier study, which indicated unexpectedly slow postnatal maturation kinetics for Th-1 associated immune function (4), we have obtained data at a range of time points during childhood between birth (cord blood) and adulthood. Our findings reveal two parallel processes at play in LPS responses during early infancy, notably the time-dependent decay of transient hyperresponsiveness with respect to production of a restricted range of cytokines by neonatal monocytes, superimposed over a more generalized pattern of age-dependent up-regulation of cytokine production that commences later during infancy.

\section{METHODS}

Subjects. Cord blood (CB) was obtained from normal full-term deliveries. Blood samples were from groups of healthy children aged 2 mo, 1 y, 4 y, and 13 y. Adult samples were obtained from healthy laboratory volunteers (median age, $31 \mathrm{y}$; range, 23-57 y). Ethics approval was obtained from the Ethics Committee of the Princess Margaret Hospital for Children, and written consent was obtained from each subject or their parents/guardians.

Cell preparation and culture. Blood was collected into an equal volume of RPMI 1640 (Cytosystems, Aberdeen, Scotland) containing preservative- and endotoxin-free heparin $(20 \mathrm{U} / \mathrm{mL})$, and cord blood (CBMC) or peripheral blood mononuclear cells (PBMC) were isolated by density gradient centrifugation and cryopreserved. Previous studies from our laboratory (17) have

Abbreviations: CB, cord blood; CBMC, cord blood mononuclear cells; LPS, lipopolysaccharide; PBMC, peripheral blood mononuclear cells; TLR, Tolllike receptor 
shown that cellular immune responses are not distorted by this process. Cryopreserved CBMC and PBMC were thawed and resuspended at $1 \times 10^{6}$ cells/mL in RPMI 1640 and 10\% FCS (JRH Biosciences, Lenexa, KS), unless otherwise stated when $10 \%$ autologous plasma was used. Cells were primed for $3 \mathrm{~h}$ with IFN- $\gamma(10 \mathrm{ng} / \mathrm{mL})$ before the addition of LPS $(1 \mathrm{ng} / \mathrm{mL}$, Alexis Corporation, Läufelfingen, Switzerland; ultrapure TLR grade), and cultured at $37^{\circ} \mathrm{C}$ with $5 \% \mathrm{CO}_{2}$. Cell pellets were collected into RNA lysis buffer (Ambion, Austin, TX) $2 \mathrm{~h}, 6 \mathrm{~h}$, or $24 \mathrm{~h}$ after the addition of LPS and stored at $-20^{\circ} \mathrm{C}$ until RNA isolation. At $24 \mathrm{~h}$, cell supernatant was also collected and stored at $4^{\circ} \mathrm{C}$ until cytokine analysis. In some experiments, CBMC cytokine production was blocked by addition of actinomycin D at $0.5 \mu \mathrm{g} / \mathrm{mL}$ (Sigma Chemical Co., St. Louis, MO). In a separate set of experiments, CD56 ${ }^{+}$cells were removed from the CBMC using CD56 microbeads (Millenyi Biotec, Sunnyvale, CA) according to manufacturer's directions.

Detection of cytokine protein. Protein levels of IL-6, IL-10, and TNF- $\alpha$ in culture supernatant were measured by in-house time-resolved fluorometry (TRF), as described in detail elsewhere (18). The limit of detection for each assay was $10 \mathrm{pg} / \mathrm{mL}$.

Quantitative PCR. Total RNA was isolated using the RNAqueous 96 well Kit (Ambion) according to the manufacturer's directions. Reverse transcription was performed using the Omniscript kit (QIAGEN, Valencia, CA) according to the manufacturer's protocol with oligo-dT (Promega, Madison, WI) and Superasin (GeneWorks, Hindmarsh, SA, Australia). Intron-spanning primers were designed in-house using Primer Express Software (Applied Biosystems, Foster City, CA). Reverse-transcribed RNA samples were diluted $1 / 5$ and quantitated by real-time PCR using QuantiTect SYBR Green Master Mix (QIAGEN) on the ABI PRISM 7900HT (Applied Biosystems). Melting curve analysis was used to assess the specificity of the assay. Copy numbers were determined by 10 -fold serial dilutions of plasmid standards and normalized to the reference gene UBE2D2 (19).

TLR4 detection on blood monocytes. Cord blood and adult PBMC were primed with IFN- $\gamma$ and stimulated with LPS $(1 \mathrm{ng} / \mathrm{mL})$ for 0,6 , and $24 \mathrm{~h}$ before harvest for flow cytometry. Each sample was incubated with biotinylated mouse anti-human TLR4 (clone HTA125, eBioscience, San Diego, CA) for $30 \mathrm{~min}$ at $4^{\circ} \mathrm{C}$, washed, and then PE-conjugated streptavidin (BD Biosciences, San Jose, CA) and FITC-conjugated mouse anti-human CD14 (clone M5E2, BD Biosciences) were added for another $30 \mathrm{~min}$ at $4^{\circ} \mathrm{C}$. Background fluorescence controls comprised PBMC incubated with anti$\mathrm{CDH}$ alone. All samples were fixed in PBS containing $0.5 \%$ formaldehyde and stored at $4^{\circ} \mathrm{C}$. Samples were collected using a 4-color FACSCalibur (BD Biosciences) and analyzed using FlowJo software (Tree Star Inc., Stanford, CA).

Intracellular cytokine detection. PBMC were primed with IFN- $\gamma$ and stimulated with LPS for $24 \mathrm{~h}$. Brefeldin A (Sigma-Aldrich, St. Louis, MO; 5 $\mu \mathrm{g} / \mathrm{mL}$ ) was added for the last $16 \mathrm{~h}$ of culture. At the end of the culture period, the cells were incubated with anti-CD3-PerCP and anti-CD14-FITC (BD Biosciences) for $30 \mathrm{~min}$ on ice, washed, then fixed with formaldehyde (BDH, $0.4 \%$ in PBS) overnight at $4^{\circ} \mathrm{C}$. Cells were washed and briefly incubated in perm-wash (0.1\% saponin (Sigma-Aldrich), 0.5\% BSA, in PBS) before biotinylated mAbs against IL- 6 or TNF- $\alpha$ (BD Biosciences) were added for 30 min on ice. After washing, streptavidin-allophycocyanin (APC) was added for $30 \mathrm{~min}$ on ice. Cytokine staining was judged by comparison with cultured but unstimulated controls.
Statistical analysis. All statistical analyses were performed using the statistical package SPSS (SPSS Inc., Chicago, IL). Differences between control and LPS-stimulated response were tested for significance using Wilcoxon matched-pairs signed-rank test for paired responses. Comparisons of responses between different age groups were made using Mann-Whitney $U$ test for unpaired responses.

\section{RESULTS}

Age-related changes in cytokine responses to LPS. LPSinduced cytokine mRNA expression was measured for each age group at the time of peak production post stimulation (data not shown for other time points) and normalized to the reference gene UBE2D2 (19), as shown in Figure 1A. The kinetics of mRNA expression were the same for the subunits of IL-12 and IL-23 and for IFN- $\gamma$ and MxA [myxovirus resistance protein $\mathrm{A}$, induced in a dose-dependent manner by type-I interferons, (20)], which all showed peak mRNA expression 6-h post-LPS stimulation. IL-18 was constitutively expressed with peak mRNA levels $2 \mathrm{~h}$ after LPS stimulation. Reduced responsiveness to stimulation was observed in the rate-limiting subunits p19 and p35 of IL-23 and IL-12, respectively, for the cord blood samples and in the 1- and 4-y-old children, such that only 13 y olds and adults showed a significant increase in expression in response to LPS-stimulation $(p<0.05)$. IL-18 expression was only significantly increased in response to LPSstimulation in adults $(p=0.021)$. The mRNA expression levels of all cytokines, including both the constitutive and stimulated levels of IL-18, showed a remarkably similar pattern whereby expression was significantly higher in $13 \mathrm{y}$ olds and adults than in cord blood or 1 and 4 y olds (the highest $p$ value is shown in the legend for Figure 1).

An additional and unexpected finding was that the IFN- $\gamma$ response in cord blood was consistently higher than in samples from infants and $4 \mathrm{y}$ olds, a pattern that is reiterated below.

Unexpectedly high inflammatory cytokine protein production by cord blood cells. In addition to the targets in Figure $1 A$, levels of the proinflammatory cytokines TNF- $\alpha$, IL- 6 , and IL-10 were also measured (as protein) at $24 \mathrm{~h}$ after LPS
A

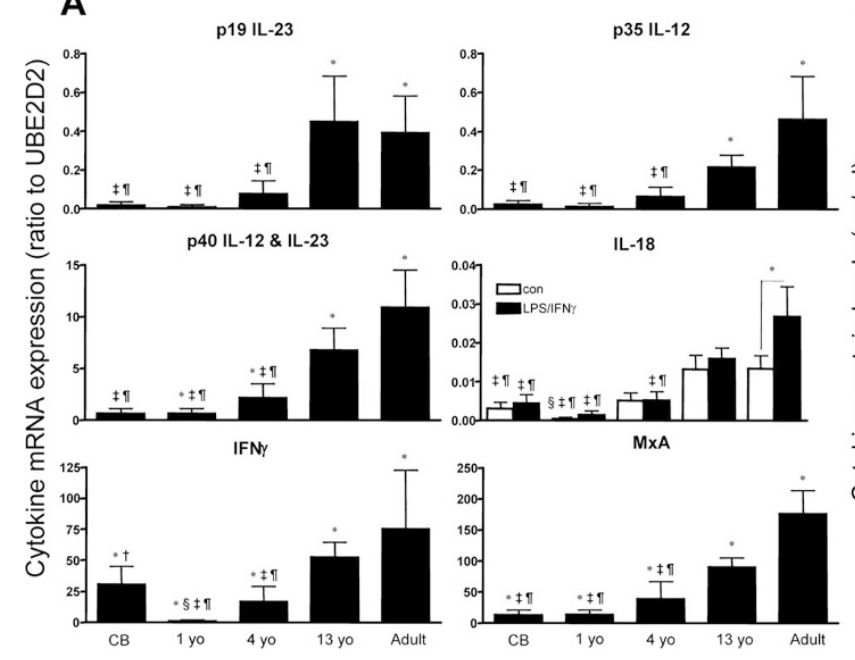

B

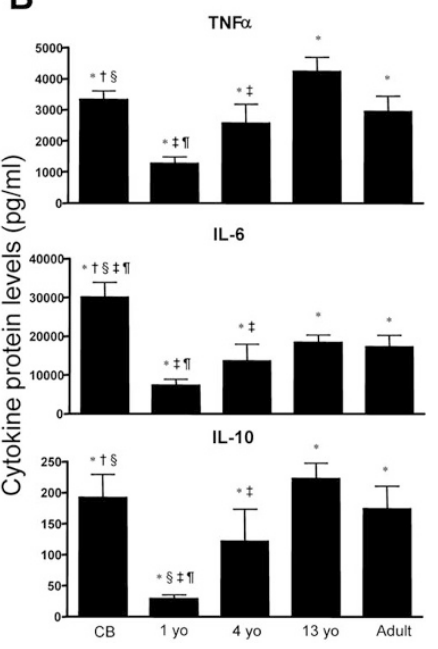

Figure 1. Age-related changes in cytokine mRNA expression and protein production following LPS stimulation. Mononuclear cells were stimulated with $\mathrm{LPS} / \mathrm{IFN} \gamma$, and (A) maximal mRNA expression was measured $6 \mathrm{~h}$ post-LPS stimulation $(\mathrm{CB}, n=10$; $1 \mathrm{y}$ olds, $n=7 ; 4$ y olds, $n=10 ; 13$ y olds, $n=10$; and adults, $n=8$ ), except for IL-18, which is expressed constitutively (open bars) and has maximal mRNA expression (black bars) at $2 \mathrm{~h}$ post-LPS stimulation (CB, $n=10 ; 1$ y olds, $n=9 ; 4$ y olds, $n=$ 7; 13 y olds, $n=9$; and adults, $n=10$ ). (B) Protein levels were determined $24 \mathrm{~h}$ postLPS stimulation ( $n=10$ per age group) and presented as mean + SE. $* p<0.050 v s$ unstimulated (control) cultures; $\uparrow p<0.01 v s$ 1 y olds; $\$ p<0.050$ vs 4 y olds; $\ddagger p<0.040$ vs 13 y olds; $\llbracket p<0.040$ vs adult. 
stimulation for all these age groups (Fig. 1B). Cord blood cells secreted significantly higher levels of these cytokines than samples from $1 \mathrm{y}$ olds $(p<0.01)$ and 4 y olds $(p<0.05)$, with production in cord cells being at similar levels to that seen in 13 y olds and adults. IL- 6 production by cord blood cells was significantly higher than in any postnatal age group $(p<$ 0.05).

High inflammatory cytokine production by CBMC is rapidly attenuated postnatally. To determine the approximate time frame within which the high levels of TNF- $\alpha$, IL-6, and IL-10 production observed in CBMC were maintained postnatally, PBMC from a subgroup of 2-mo-old infants $(n=8)$ were analyzed separately for LPS-induced cytokine secretion after LPS-stimulation for $24 \mathrm{~h}$ and compared with data from the cord blood and samples from 1 y olds. There was significantly lower production of TNF- $\alpha(p=0.001)$, IL-6 ( $p=$ $0.001)$, and IL-10 ( $p=0.001)$ by the 2-mo-old infant PBMC relative to the level produced by CBMC (Fig. 2), the levels observed being equivalent to that seen with PBMC from $1 \mathrm{y}$ olds.

Employing an additional series of samples, we then tested whether the method of delivery influenced production of inflammatory cytokines by CBMC. Similar levels of the cytokines TNF- $\alpha$, IL-6, and IL-10 were produced by LPS/IFN$\gamma$-stimulated CBMC obtained from those that experienced labor and those that did not experience labor (Fig. 3).

CB cells have higher and sustained TLR4 expression following LPS stimulation. The level of expression of the LPS receptor, TLR4 was measured on CBMC, infant and adult PBMC before $(0 \mathrm{~h})$ and at $6 \mathrm{~h}$ and $24 \mathrm{~h}$ post LPS stimulation (Fig. 4). TLR4 expression was found predominantly on $\mathrm{CD}_{14}{ }^{+}$monocytes, which were proportionally highest in number amongst CBMC $(14.89 \pm 1.72 \%$, compared with $8.13 \pm 1.16 \%$ in adult PBMC; $p=0.011$ ). Before LPS stimulation, there were similar low levels of expression of TLR4 on $\mathrm{CD}_{1} 4^{+}$cells from the different age groups. The level of surface TLR4 expression increased rapidly following LPSstimulation (Fig. 4), particularly in the CBMC population. Of particular note, TLR4 expression was sustained at significantly higher levels in $\mathrm{CD} 14^{+} \mathrm{CBMC}$ than in the other age groups. This latter observation of enhanced TLR4 up-regulation on LPS/ IFN- $\gamma$ stimulated CBMC was subsequently confirmed employing two additional independent groups of four cord blood and adult monocytes (not shown). It is additionally noteworthy that the TLR4 hyperresponsiveness evident in CBMC was not sustained into infancy, and instead surface expression post LPS stimulation was short-lived in infant CD14 ${ }^{+}$PBMC relative to cord and adult.

Cellular sources of inflammatory cytokines. CBMC and adult PBMC were stimulated with LPS/IFN- $\gamma$ and double stained for extracellular surface expression of CD3 or CD14, together with intracellular IL-6 or TNF- $\alpha$. As shown in Table 1 and Figure 5, expression of intracellular cytokine post stimulation in both age groups was most frequent amongst $\mathrm{CD} 14^{+}$monocytes, with low expression in the $\mathrm{CD}^{+}$cells and no detectable cytokine staining in the $\mathrm{CD}^{-}$and $\mathrm{CD} 14^{-}$ cell populations. Moreover, the percentage of cytokine producing monocytes was in the order of double in CBMC
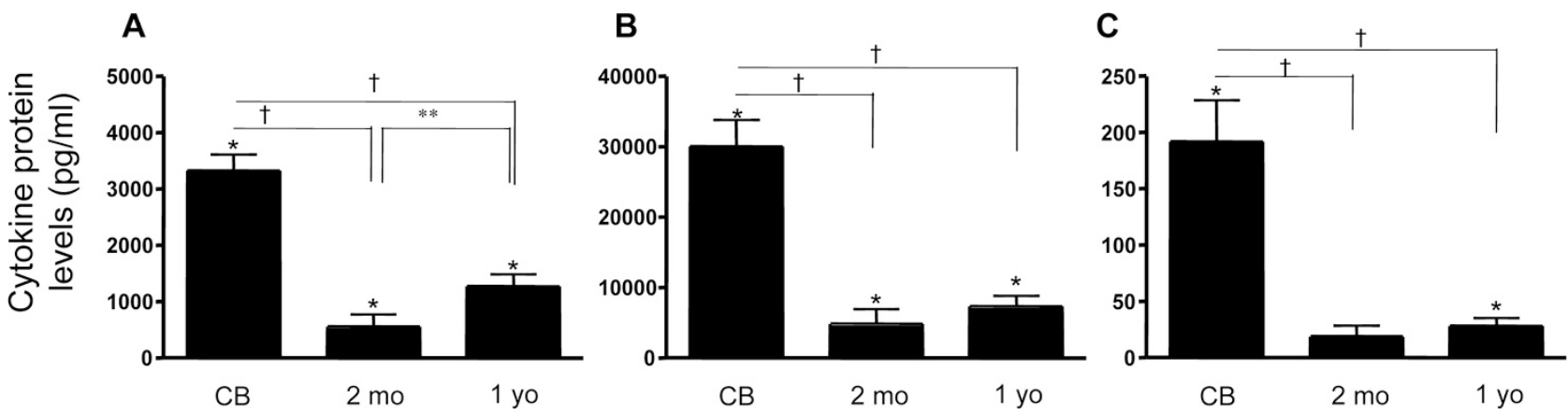

Figure 2. TNF- $\alpha(A)$, IL-6 (B), and IL-10 $(C)$ protein production following LPS-stimulation in 2-mo-old infants. Mononuclear cells from children aged 2 mo old $(n=8)$ were stimulated with LPS/IFN- $\gamma$ and protein levels were determined at $24 \mathrm{~h}$ and are presented as mean \pm SE. The values for CB and samples from 1 y olds are shown Figure $1 B$ and reproduced here for clarity. $* p<0.012 v s$ controls; $\dagger p=0.001, * * p=0.012$.
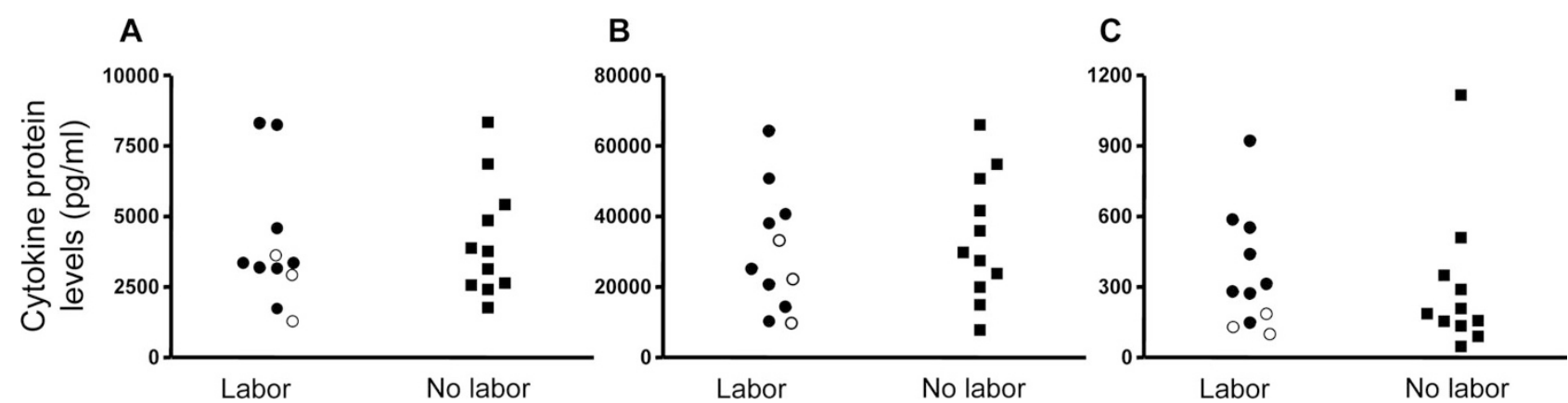

Figure 3. The method of delivery does not affect TNF- $\alpha(A)$, IL-6 $(B)$, and IL-10 $(C)$ production by LPS-stimulated CBMC. CBMC collected from births that experienced labor $(\bullet$, spontaneous vaginal delivery, $n=8)$ and emergency caesarean $(\bigcirc, n=3)$ and those that did not experience labor $(\boldsymbol{\square}$, elective caesarean, $n=11$ ) were stimulated with LPS/IFN- $\gamma$ and cytokine levels determined at $24 \mathrm{~h}$. Delta values (treatment - control) are presented as a scatter plot. 


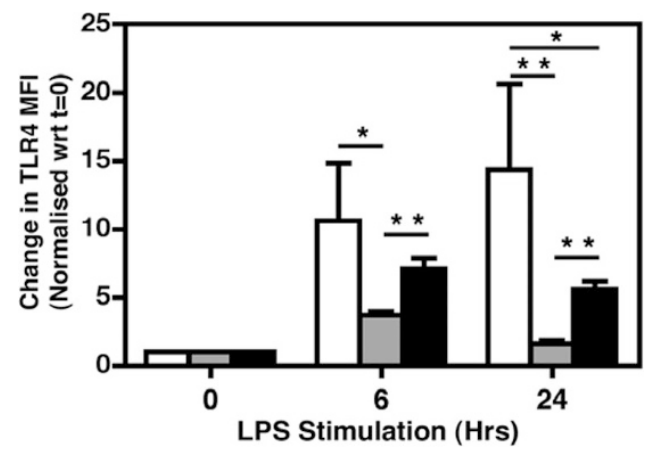

Figure 4. Age-dependent changes in TLR4 expression on CD14 ${ }^{+}$cells from CBMC, $1 \mathrm{y}$ old and adult PBMC following LPS-stimulation. CBMC (open bars) and PBMC from 1 y olds (gray bars) and adults (black bars, $n=4$ per group) were stimulated with LPS/IFN- $\gamma$ for 0,6 , or $24 \mathrm{~h}$ and stained for CD14 and TLR4 expression. Changes in TLR4 MFI (mean \pm SE) relative to background controls, normalized with respect to time 0 h. ${ }^{*} p=0.05$ and $* * p=0.004$

Table 1. Monocytes are responsible for the IL-6 and TNF- $\alpha$ cytokine production following LPS stimulation

\begin{tabular}{lcc}
\hline & CBMC & Adult PBMC \\
\hline$\% \mathrm{CD}^{+} \mathrm{IL}-6^{+}$ & $0.29 \pm 0.06$ & $0.39 \pm 0.03$ \\
$\% \mathrm{CD} 14^{+} \mathrm{IL}^{+}$ & $5.13 \pm 1.27$ & $2.59 \pm 0.66$ \\
$\% \mathrm{CD} 3^{+} \mathrm{TNF}^{+}$ & $0.27 \pm 0.03$ & $0.40 \pm 0.05$ \\
$\% \mathrm{CD} 14^{+} \mathrm{TNF} \alpha^{+}$ & $4.47 \pm 0.90$ & $2.22 \pm 0.42$ \\
\hline
\end{tabular}

Adult and CB samples were stimulated with LPS/IFN- $\gamma$ and intracellular cytokine measured. The proportion of $\mathrm{T}$ cells $\left(\mathrm{CD}^{+} \mathrm{CD} 14^{-}\right)$and monocytes $\left(\mathrm{CD} 14^{+}\right)$expressing TNF- $\alpha$ and IL-6 within the total cell population was determined for each sample $(n=4)$ and are presented as mean \pm SE. No TNF- $\alpha$ - or IL- 6 -positive cells were detected in the $\mathrm{CD}^{-}$or $\mathrm{CD} 14^{-}$populations.

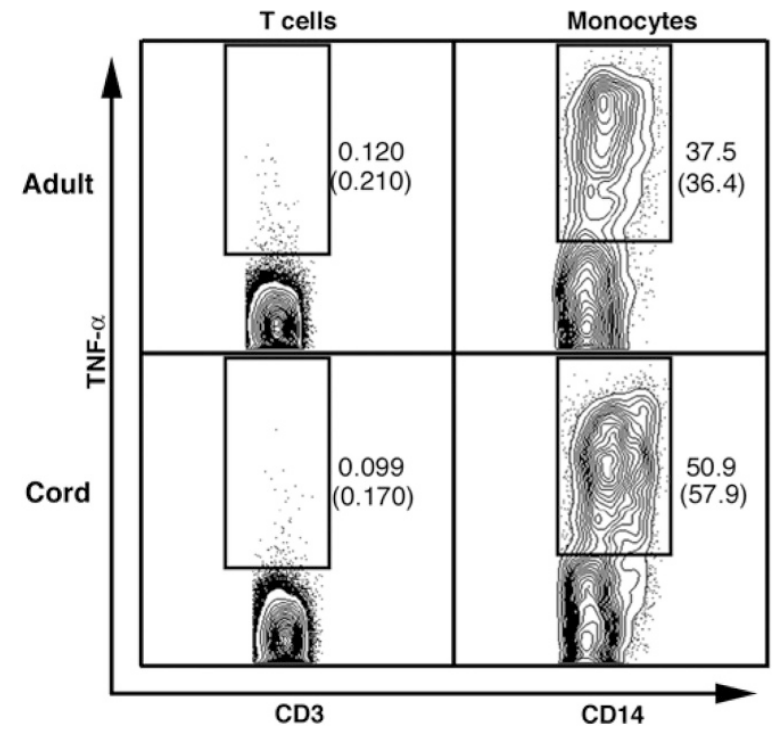

Figure 5. Monocytes are the chief source of TNF- $\alpha$ and IL-6 upon LPS stimulation. Adult and cord blood samples were stimulated with LPS/IFN- $\gamma$ for $24 \mathrm{~h}$ and intracellular cytokines detected. Representative plots are shown together with the percentage of CD3 or CD14 cells positive for TNF- $\alpha$, and the percentage of CD3 or CD14 cells positive for IL- 6 are shown in parenthesis.

relative to adult PBMC. Additionally, overall mononuclear cell counts per unit volume of blood were 2-3-fold higher in cord blood than in adults (not shown).
Follow-up experiments were performed to determine whether $\mathrm{CD}^{2} 6^{+} \mathrm{NK}$ cells also contributed to the CBMC responses, as the frequency of this cell type is known to be elevated among neonates. However, in a series of four replicate samples, depletion of $\mathrm{CD}^{+} 6^{+}$cells did not reduce levels of IL-6, IL-10, or TNF- $\alpha$ production by LPS/IFN- $\gamma$ stimulated PBMC (data not shown). Additionally, supplementation of stimulated cultures with actinomycin D blocked $100 \%$ of resultant cytokine production (data not shown), demonstrating that these cytokine responses involve de novo protein synthesis as opposed to secretion of preformed cytokine protein (e.g. from intracellular granules).

Recent evidence (7) suggests that deficiency in serum-borne carrier molecules may also contribute to low-level LPS responsiveness in early life. The principal assay system used for this study used FCS in which levels of these molecules are not limiting, which may have contributed to the high responses of CBMC. Accordingly, we carried out additional experiments contrasting LPS responses of CBMC and 1-y-olds in autologous plasma versus FCS. Figure 6 demonstrates that, although FCS does boost overall IL-6, TNF- $\alpha$, and TLR4 responses to LPS/IFN- $\gamma$, the relativity between response levels at respective ages is maintained in autologous plasma. It is noteworthy that the suboptimal responses to LPS observed in the absence of IFN- $\gamma$ priming were less influenced by these serum effects at the concentration tested, but this may not be the case in higher levels of autologous serum (not tested).

\section{DISCUSSION}

The early postnatal period represents the life phase during which susceptibility to microbial infection is highest, and this is generally ascribed to a range of transient developmental deficiencies in innate and adaptive immune mechanisms. There have been many reports indicating that the immune system is deficient in capacity to mount Th1 responses at birth $(13,14)$ and later during infancy $(21)$, but there have, in contrast, been only limited studies (4) on how this response capacity develops with age.

We addressed this issue in the present study by focusing on a broad range of classical Th1 cytokines and additional proinflammatory and regulatory cytokines produced in response to LPS by PBMC from different age groups. The developmental pattern observed spanning the period of infancy (1 y) to adulthood was comparable for all the cytokines studied. Notably, response capacity during infancy was low, and increased slowly during the preschool years, generally approaching the adult range in adolescence. This pattern closely mirrors our earlier findings for IL-12p70 (4). The consistency is compatible with the operation of common underlying regulatory mechanisms, which control effector gene expression in mononuclear cells throughout life.

As LPS signals through TLR4, age-related changes in TLR4 function may be responsible for the trend observed. This possibility is suggested by findings (7) indicating significant differences between CD14 and TLR4 function in adult and neonatal monocytes. Of note, this comparable basal TLR4 


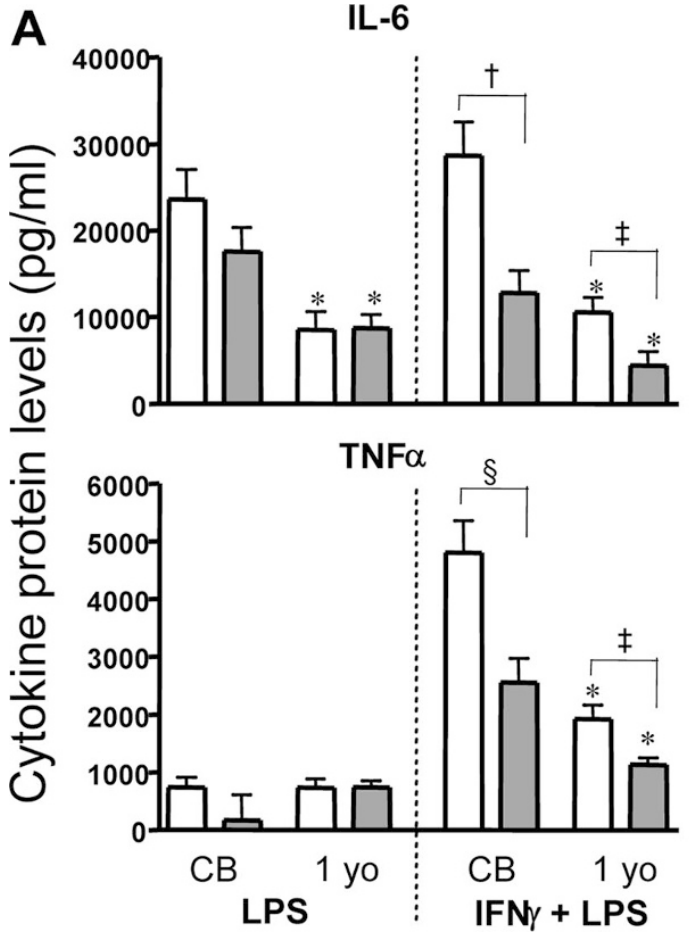

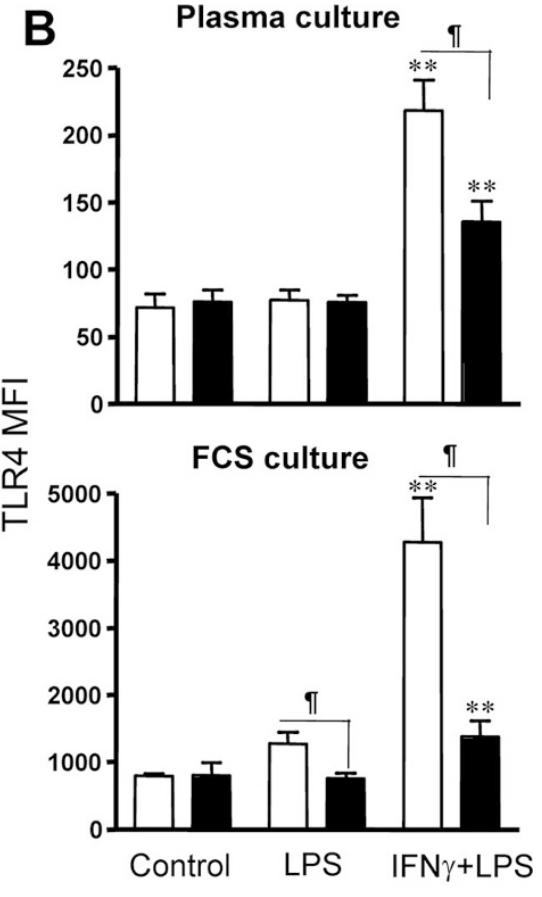

Figure 6. Age-related changes in cytokine responses following LPS stimulation in $10 \%$ FCS or $10 \%$ autologous plasma. $(A)$ CBMC and 1-y-old PBMC were cultured with $10 \%$ FCS (open bars) or $10 \%$ autologous plasma (shaded bars), were left unprimed or primed with IFN- $\gamma$, and cytokine protein levels ( $n=8$ per age group) were measured $24 \mathrm{~h}$ post LPS stimulation. (B) TLR4 MFI was measured $24 \mathrm{~h}$ post LPS stimulation on CB (open bars, $n=4$ ) and 1-y-old infant monocytes (black bars, $n=4$ ), and results from a representative experiment presented as mean $\pm \mathrm{SE}$. ${ }^{*} p<$ 0.05 vs $\mathrm{CB} ;{ }^{* *} p<0.012$ vs control cultures; $\dagger p=0.05 ; \ddagger p=0.012 ; \S p=0.017$; $\mathbb{I} p=0.029$. expression but deficient TLR4-mediated LPS-induced TNF- $\alpha$ production by neonatal monocytes cultured in autologous plasma has been attributed principally to the elevated concentrations of cAMP in the cytosol of neonatal CBMC resulting in suppression of TNF- $\alpha$ but preservation of IL- 6 production (22) as opposed to serum defects. It should be noted that the present study focused on the functions of the monocytes per se and deliberately circumvented any potential plasma-related differences via the use of FCS in monocyte assays from all age groups. Our findings indicate similar basal levels of TLR4 expression on adult monocytes and those from 1-y-old infants as per Levy et al. (22), however, up-regulation of translocation of intracellular TLR4 to the cell surface following LPS stimulation in our study was short lived in infant monocytes relative to adults, declining markedly between 6 and 24 h post stimulation (Fig. 4), and this may account for the attenuated cytokine responses in the infants (Fig. 1).

The situation with respect to cord blood cytokine responses is more complex. As noted in Figure 1, capacity to produce a range of cytokines, notably IL-12, IL-18, IL-23, and type-I IFN, are uniformly reduced in cord and infant monocytes relative to later ages, suggesting persistence into postnatal life of negative control mechanisms operative in the fetus, which are believed to be central to protection of the placenta (23). However, a group of cytokines do not fit this pattern, notably TNF- $\alpha$, IL-6, IL-10 (Fig. $1 B$ ), and IFN- $\gamma$ (Fig. 1A), being instead expressed at adult-equivalent or higher levels in cord monocytes compared with the markedly attenuated expression levels of their infant counterparts. Comparably elevated IL-8 responses have also been reported in cord blood monocytes (10). This implies either a marked disparity between regulatory mechanisms in monocytes from the different age groups, or alternatively some form of preactivation of the cord cells, with selective downstream effects on cytokine gene expres- sion. Given that the presence of elevated levels of this same group of cytokines in cord blood is a known marker of birth trauma (24), we tested the possibility that stress associated with labor before cord blood collection may account for the heightened TNF- $\alpha$, IL-6, IL-10, and IFN- $\gamma$ responses observed. However, as demonstrated in Figure 3, monocyte responses were not detectably different between samples collected after elective cesarean versus vaginal delivery. It is noteworthy that T-cell production of IL- 6 and TNF- $\alpha$ is also reportedly enhanced in cord blood and this enhancement is also independent of mode of delivery (25).

Significant differences, however, were detected between cord blood and infant monocytes in relation to TLR4 expression. Recent studies suggest that TLR4-dependent LPSinduced TNF- $\alpha$ and IL-6 responses are markedly attenuated in neonatal monocytes, when LPS stimulation is performed in the presence of neonatal plasma $(6,7)$, but it is not clear whether this deficiency is entirely or only partially due to deficiencies in LPS carriers and/or the presence of inhibitors in neonatal blood. As noted in Figure 4, up-regulation of surface expression of TLR4 on monocytes following LPS stimulation in the presence of serum known to be fully supportive of TLR4 function (i.e. FCS), revealed more rapid and sustained TLR4 translocation to the cell surface in neonatal monocytes, relative to other age groups. We hypothesize that this enhanced TLR4 activity in cord blood monocytes, coupled with their increased frequency within the circulating white cell compartment and per unit volume of blood, underlies the selective enhancement of TNF- $\alpha$, IFN- $\gamma$, IL- 6 , and IL-10 responses observed in LPS-stimulated cord blood. Furthermore, IL-6 may also be responsible for the elevated and sustained level of TLR4 surface expression on monocytes (26), as cord blood monocytes had significantly higher TLR4 expression and higher IL-6 production compared with adults, 
which were significantly higher in both regards than the 1 -y-olds.

The nature of the molecular mechanism(s) underlying the differences between regulation of the latter group of cytokines versus IL-12, IL-18, IL-23, and type-I IFN in neonatal monocytes remains to be determined. In this context, it has been established that responses to LPS mediated via TLR4 can be divided into a component that is dependent upon the adaptor protein myeloid differentiation factor antigen 88 (MyD88), and a MyD88-independent response, which is dependent upon the adaptor protein TOLL/IL-1 receptor domain-containing adaptor inducing IFN- $\beta$ (TRIF).

It is of interest to note that the cytokines that are hyperexpressed by CBMC relative to their infant counterparts (TNF- $\alpha$, IFN- $\gamma$, IL-6, and IL-10) are uniformly MyD88dependent, whereas those that show equivalently attenuated response levels in the cord blood and infant groups compared with the later age groups (p35IL-12, IL-18, p19IL-23) are controlled via TRIF-dependent mechanisms (27,28). A finding that superficially appears to complicate this issue is that MyD88 levels as determined in LPS-stimulated cord blood monocytes by Western blotting are lower than in adult monocytes (8), however, this may be due to the use of LPS-carrierdeficient cord blood plasma in the assay system, as opposed to an intrinsic defect in the neonatal monocytes themselves.

In conclusion, there appears to be major differences in developmental regulation of TRIF-dependent versus MyD88dependent cytokines in mononuclear cells in early life. Further research is required to more fully define the molecular mechanisms underlying these differences. It also remains to be determined whether the transient hyperresponsiveness of neonatal monocytes in regards to production of TNF- $\alpha$, IL-6, IL-10, and IFN- $\gamma$ have any pathologic implications, for example, in the context of responses of newborns to microbial pathogens.

\section{REFERENCES}

1. Holt PG, Jones CA 2000 The development of the immune system during pregnancy and early life. Allergy 55:688-697

2. Kawai T, Akira S 2005 Pathogen recognition with Toll-like receptors. Curr Opin Immunol 17:338-344

3. Scott ME, Kubin M, Kohl S 1997 High level interleukin-12 production, but diminished interferon-gamma production, by cord blood mononuclear cells. Pediatr Res 41:547-553

4. Upham JW, Lee PT, Holt BJ, Heaton T, Prescott SL, Sharp MJ, Sly PD, Holt PG 2002 Development of interleukin-12-producing capacity throughout childhood. Infect Immun 70:6583-6588

5. Chelvarajan RL, Collins SM, Doubinskaia IE, Goes S, Van Willigen J, Flanagan D, De Villiers WJ, Bryson JS, Bondada S 2004 Defective macrophage function in neonates and its impact on unresponsiveness of neonates to polysaccharide antigens. J Leukoc Biol 75:982-994

6. Forster-Waldl E, Sadeghi K, Tamandl D, Gerhold B, Hallwirth U, Rohrmeister K, Hayde M, Prusa AR, Herkner K, Boltz-Nitulescu G, Pollak A, Spittler A 2005 Monocyte toll-like receptor 4 expression and LPS-induced cytokine production increase during gestational aging. Pediatr Res 58:121-124
7. Levy O, Zarember KA, Roy RM, Cywes C, Godowski PJ, Wessels MR 2004 Selective impairment of TLR-mediated innate immunity in human newborns: neonatal blood plasma reduces monocyte TNF-alpha induction by bacterial lipopeptides, lipopolysaccharide, and imiquimod, but preserves the response to R-848. J Immunol 173:4627-4634

8. Yan SR, Qing G, Byers DM, Stadnyk AW, Al-Hertani W, Bortolussi R 2004 Role of MyD88 in diminished tumor necrosis factor alpha production by newborn mononuclear cells in response to lipopolysaccharide. Infect Immun 72:1223-1229

9. Berner R, Welter P, Brandis M 2002 Cytokine expression of cord and adult blood mononuclear cells in response to Streptococcus agalactiae. Pediatr Res 51:304309

10. Dembinski J, Behrendt D, Reinsberg J, Bartmann P 2002 Endotoxin-stimulated production of IL- 6 and IL- 8 is increased in short-term cultures of whole blood from healthy term neonates. Cytokine 18:116-119

11. Goriely S, Vincart B, Stordeur P, Vekemans J, Willems F, Goldman M, De Wit D 2001 Deficient IL-12(p35) gene expression by dendritic cells derived from neonatal monocytes. J Immunol 166:2141-2146

12. Angelone DF, Wessels MR, Coughlin M, Suter EE, Valentini P, Kalish LA, Levy O 2006 Innate immunity of the human newborn is polarized toward a high ratio of IL-6/TNF- $\alpha$ production in vitro and in vivo. Pediatr Res 60:205-209

13. La Pine TR, Joyner JL, Augustine NH, Kwak SD, Hill HR 2003 Defective production of IL-18 and IL-12 by cord blood mononuclear cells influences the T helper-1 interferon gamma response to group B Streptococci. Pediatr Res 54:276-281

14. Langrish CL, Buddle JC, Thrasher AJ, Goldblatt D 2002 Neonatal dendritic cells are intrinsically biased against Th-1 immune responses. Clin Exp Immunol 128:118-123

15. White GP, Watt PM, Holt BJ, Holt PG 2002 Differential patterns of methylation of the IFN-gamma promoter at $\mathrm{CpG}$ and non-CpG sites underlie differences in IFNgamma gene expression between human neonatal and adult CD45RO- T cells J Immunol 168:2820-2827

16. Hayes MP, Wang J, Norcross MA 1995 Regulation of interleukin-12 expression in human monocytes: selective priming by interferon-gamma of lipopolysaccharideinducible p35 and p40 genes. Blood 86:646-650

17. Upham JW, Holt BJ, Baron-Hay MJ, Yabuhara A, Hales BJ, Thomas WR, Loh RK, O'Keeffe PT, Palmer L, Le Souef PN, Sly PD, Burton PR, Robinson BW, Holt PG 1995 Inhalant allergen-specific T-cell reactivity is detectable in close to $100 \%$ of atopic and normal individuals: covert responses are unmasked by serum-free medium. Clin Exp Allergy 25:634-642

18. Rowe J, Heaton T, Kusel M, Suriyaarachchi D, Serralha M, Holt BJ, de Klerk N, Sly PD, Holt PG 2004 High IFN-gamma production by CD8 + T cells and early sensitization among infants at high risk of atopy. J Allergy Clin Immunol 113:710-716

19. Hamalainen HK, Tubman JC, Vikman S, Kyrola T, Ylikoski E, Warrington JA, Lahesmaa R 2001 Identification and validation of endogenous reference genes for expression profiling of $\mathrm{T}$ helper cell differentiation by quantitative real-time RTPCR. Anal Biochem 299:63-70

20. von Wussow P, Jakschies D, Hochkeppel HK, Fibich C, Penner L, Deicher H 1990 The human intracellular Mx-homologous protein is specifically induced by type I interferons. Eur J Immunol 20:2015-2019

21. Rowe J, Macaubas C, Monger T, Holt BJ, Harvey J, Poolman JT, Loh R, Sly PD, Holt PG 2001 Heterogeneity in diphtheria-tetanus-acellular pertussis vaccinespecific cellular immunity during infancy: relationship to variations in the kinetics of postnatal maturation of systemic th1 function. J Infect Dis 184:80-88

22. Levy O, Coughlin M, Cronstein BN, Roy RM, Desai A, Wessels MR 2006 The adenosine system selectively inhibits TLR-mediated TNF-alpha production in the human newborn. J Immunol 177:1956-1966

23. Wegmann TG, Lin H, Guilbert L, Mosmann TR 1993 Bidirectional cytokine interactions in the maternal-fetal relationship: is successful pregnancy a TH2 phenomenon? Immunol Today 14:353-356

24. Macaubas C, de Klerk NH, Holt BJ, Wee C, Kendall G, Firth M, Sly PD, Holt PG 2003 Association between antenatal cytokine production and the development of atopy and asthma at age 6 years. Lancet 362:1192-1197

25. Keski-Nisula L, Hirvonen MR, Roponen M, Heinonen S, Pekkanen J 2004 Spontaneous and stimulated interleukin- 6 and tumor necrosis factor-alpha production at delivery and three months after birth. Eur Cytokine Netw 15:67-72

26. Tamandl D, Bahrami M, Wessner B, Weigel G, Ploder M, Fürst W, Roth E, Boltz-Nitulescu G, Spittler A 2003 Modulation of toll-like receptor 4 expression on human monocytes by tumor necrosis factor and interleukin-6: tumor necrosis factor evokes lipopolysaccharide hyporesponsiveness, whereas interleukin-6 enhances lipopolysaccharide activity. Shock 20:224-229

27. Goriely S, Molle C, Nguyen M, Albarani V, Haddou NO, Lin R, De Wit D, Flamand V, Willems F, Goldman M 2006 Interferon regulatory factor 3 is involved in Toll-like receptor 4 (TLR4)- and TLR3-induced IL-12p35 gene activation. Blood 107:1078-1084

28. Weighardt H, Jusek G, Mages J, Lang R, Hoebe K, Beutler B, Holzmann B 2004 Identification of a TLR4- and TRIF-dependent activation program of dendritic cells. Eur J Immunol 34:558-564 